Journal of Engineering and Applied Sciences 14 (Special Issue 5): 9162-9170, 2019

ISSN: 1816-949X

(C) Medwell Journals, 2019

\title{
Influence of Flanged Diffuser on Performance of Diffuser Augmented Wind Turbine
}

\author{
${ }^{1,2}$ Balasem Abdulameer Jabbar, ${ }^{1}$ Nor Zelawati Binti Asmuin, ${ }^{1}$ Sofian Bin Mohd, \\ ${ }^{1,2}$ Mohammed Najeh Nemah, ${ }^{1}$ Salih Meri, ${ }^{1}$ Mohamad Nur Hidayat Mat and \\ ${ }^{1}$ Ayad Jasim Jabber \\ ${ }^{1}$ Faculty of Mechanical and Manufacturing Engineering, \\ University Tun Hussein Onn Malaysia (UTHM), Batu Pahat, \\ Johor, Malaysia \\ ${ }^{2}$ Engineering Technical College of Najaf, Al-Furat Al-Awsat Technical University, Najaf, Iraq \\ balasemalquraishi@gmail.com
}

\begin{abstract}
Enclosing of horizontal axis wind turbine in diffuser is among techniques of wind power augmentation, especially, in urban areas. In this study, a small scale of Flanged Diffuser Augmented Wind Turbine (FDAWT) was presented in a two flanges angles configurations of 0 and $5^{\circ}$. The models of rotor and diffusers were fabricated and experimented in the wind tunnel. The experimental tests were conducted to calculate the power at a different wind velocities ranged 5-9 m/sec. The performance tests were in terms of power coefficient and torque coefficient as a function of the tip speed ratio. The results show a significant increase in the power coefficient of FDAWT up to 1.58 compared to Non-Flanged Diffuser Augmented Wind Turbine (NFDAWT) while the augmentation factor in power coefficient reached to 2.8 compared to Bare Horizontal Axis Wind Turbine (BHAWT). On another hand, the experiments results were validated with CFD simulation results for all cases within accepted error ratio. Moreover, CFD provided a clear visualization for the flow across wind turbine.
\end{abstract}

Key words: Wind energy, power augmentation, DAWT, HAWT, NFDAWT, BHAWT

\section{INTRODUCTION}

Wind power systems, represented by a wind turbines have been the focus of interest of scientists and researchers in the past decades. Flowing of wind through the turbine rotor leads to the production of mechanical energy that can be used in many applications, especially, to produce electricity. However, power produced by wind turbine is dependent on the Betz limit an ideal type can extract only $59.3 \%$ of incoming energy in stream-tube by turbine blades (Libii and Drahozal, 2012; Igra, 1981) various types of wind turbine exist in different sizes, Horizontal Axis Wind Turbine (HAWT) is one of these types. HAWT that have a rotor diameter of $1.25 \mathrm{~m}$ or less called a micro wind turbine. This type of turbine can be used to produce power in urban areas (Peacock et al., 2008; Gipe, 1999). Several studies have been conducted to predict and develop the performance of HAWT. Some of these studies have been carried out by practical tests, others have been analysed using programs such as CFD where some of these studies were validated with experiments results.
Improving of HAWT performance can achieved by shrouded the turbine in a diffuser in this case its called Diffuser Augmented Wind Turbine (DAWT). Many studies were conducted in this field, the augmentation of power factor was achieved of 2-5 (Ohya et al., 2017). The power coefficient and optimum tip speed ratio $(\bullet)$ for DAWT much higher than bare turbine. The reason of tip speed ratio increase because increase of mass flow rate through rotor plane where this increase produced from the pressure drop at diffuser outlet, so, the rotor need to rotating with a higher rpm (Ohya et al., 2017).

Since, DAWT performance enhancement depends on several factors including the diffuser shape and geometries, the diffuser parameters design are most important factors affected on the performance (Jafari and Kosasih, 2014). The diffuser with a flange at the exit at the proper height can increase wind velocity when augmented by the power of DAWT. The presence of flange creates pressure drop at diffuser outlet due to vortex formation caused draws more wind to diffuser as shown in Fig. 1, so, flange height is considered one of the important geometric features that contribute effectively to improve the diffuser

Corresponding Author: Balasem Abdulameer Jabbar, Faculty of Mechanical and Manufacturing Engineering, University Tun Hussein Onn Malaysia (UTHM), Batu Pahat, Johor, Malaysia, balasemalquraishi@gmail.com 


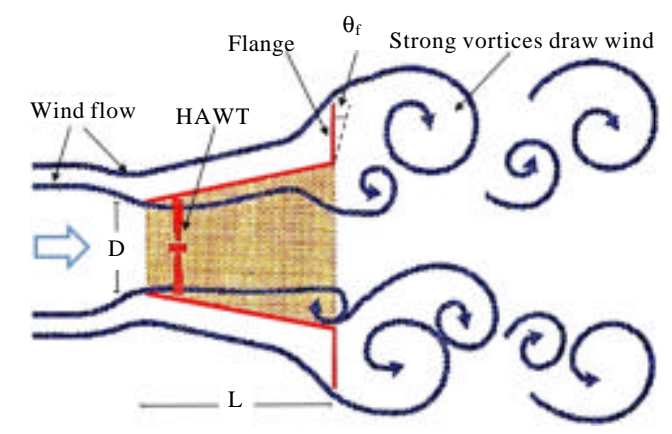

Fig. 1: Schematic view of flow mechanism around a flanged diffuser

aerodynamic performances (Ohya et al., 2008, 2017; Kosasih and Tondelli, 2012 and Kardous et al., 2013). Also, in the presence of flanged diffuser for DAWT, a significant performance benefits can be accomplished overcoming Betz limit (Tourlidakis et al., 2013; Soomro et al., 2016). Where power augmentation of wind turbine within flanged diffuser up to 4-5 times of bare turbine at the same diameter. In other hand because of the presence of flange at the outlet of diffuser helps DAWT always to face the direction of approaching wind (Ohya et al., 2008, 2017). The effect of the flange at the outlet of a diffuser is usually expressed as flange height to rotor diameter ratio (H/D). So, in study flange effect on performance of DAWT by Kosasih and Tondelli (2012) with different $\mathrm{H} / \mathrm{D}$ values as 0 (no flange), 0.15 and 0.2 in DAWT with diffuser length to rotor diameter $(\mathrm{L} / \mathrm{Dr})=0.63$, diffuser angle $\cdot=12^{\circ}$. They have been observed that increasing of $\mathrm{H} / \mathrm{D}$ lead to an increase in $\mathrm{C}_{\mathrm{p}}$. The power increase is further dependent on the flange height of the diffuser, the highest power increase was observed for multi-rotor system with an H/D of 0.1 introduced by Goltenbott et al. (2017).

Moreover, a $3 \mathrm{~kW}$ downwind type wind turbine with a rotor diameter of $2.5 \mathrm{~m}$ generated 2.5 times more power with a compact wind-Lens (flanged diffuser) than the same turbine without a wind-Lens in the field experiment (Ohya, 2014). For same turbine, the rotational speed of the rotor blade of wind turbine with a flanged diffuser was about 1.35 times compared without the flanged diffuser (Wang et al., 2015). On another hand, the flange angle $\left(\bullet_{\mathrm{f}}\right)$ can be considered as a minor parameter which can effect on the diffuser performance as mention in the simulation study which was conducted by El-Zahaby et al. (2017) for 2D axis ymmetric diffuser model $\left(\mathrm{L} / \mathrm{D}=1.5, \bullet=3.18^{\circ}\right.$ and $\left.\mathrm{H} / \mathrm{D}=0.25\right)$.

In a previous study, a developed flanged diffuser design was presented in a two models of $\bullet_{\mathrm{f}}=0^{\circ}$ and ${ }_{\mathrm{f}}=$ $5^{\circ}$. The inlet diffuser Diameter (D) $16 \mathrm{~cm}$ with $\mathrm{L} / \mathrm{D}=0.5$, $\mathrm{H} / \mathrm{D}$ of 0.2 and diffuser angle of $12^{\circ}$. CFD simulation proved that presence of flange at diffuser outlet with a suitable height increases the diffuser efficiency. The results show an increasing in flow velocity at $1 \mathrm{~cm}$ (0.0625 D a distance from diffuser inlet) along the position of rotor radius $(7.7 \mathrm{~cm})$. The simulation was conduct at a different range $1-15 \mathrm{~m} / \mathrm{sec}$ of inlet flow velocities. The average velocity increase was 1.44 for $\bullet_{\mathrm{f}}=5^{\circ}$ while it reaches to 1.47 for ${ }_{\mathrm{f}}=0^{\circ}$. These diffuser was designed to enclose a small scale HAWT rotor which presented in the previous study (Al-quraishi et al., 2019) where an experiment and CFD simulation were carried out to compare effect of presence the diffuser without flange on turbine performance.

In the present study, an experimental test was carried out to study the performance of a small scale DAWT with flanged diffuser. The experiments performance was in terms of power, power coefficient and torque coefficient which were validated with CFD results. The study also included a comparison the performance of Flanged Diffuser Augmented Wind Turbine (FDAWT) with the previous models of a Non-Flanged Diffuser Augmented Wind Turbine (NFDAWT) and BHAWT presented in previous study.

\section{MATERIALS AND METHODS}

Experimental set up: In this study, a small HAWT rotor model was same that used in previous study (Al-quraishi et al., 2019) which has three twisted blades of NACA SD 8000 with rotor diameter of $15.4 \mathrm{~cm}$. While the diffuser model used that was presented in the previous CFD study (Balasem et al., 2018). The length and inlet diameter of diffuser are 8 and $16 \mathrm{~cm}$, the diffuser angle of $12^{\circ}$. The flange height is $2.4 \mathrm{~cm}$ were used in $2^{\circ}$ configurations of flange angles are $\bullet_{\mathrm{f}}=0^{\circ}$ and $\bullet_{\mathrm{f}}=5^{\circ}$. The prototypes of rotor (containing three blades and hub) and diffusers were modelled using solid work 2017 then they manufactured from RGD450 material using polyjet 3D printing technology as describe in Fig. 2.

The wind tunnel of FKMP, UTHM with test section of $125 \times 40 \times 40 \mathrm{~cm}$ is used which can produced a maximum wind velocity of $40 \mathrm{~m} / \mathrm{sec}$. The FDAWT is placed at a distance of $60 \mathrm{~cm}$ from test section inlet (Al-quraishi et al., 2019). The turbine is attached to a 3-phase AC 12 watt alternator generator which connected to a 6-diode full wave rectifier to convert the suppling power to a 1-phase DC (Al-quraishi et al., 2019; Lee et al., 2016) (Fig. 3).

The Fluke 922 digital airflow meter with pitot tube used to measure the velocity and pressure of inlet air (Anonymous, 2006). The angular velocity of the wind turbine was measured using non-contact type, Digital Tachometer 'DT-2234B' (RS 445-9557) (Anonymous, 2019). The power calculations of FDAWT were performed 
J. Eng. Applied Sci., 14 (Special Issue 5): 9162-9170, 2019

(a)

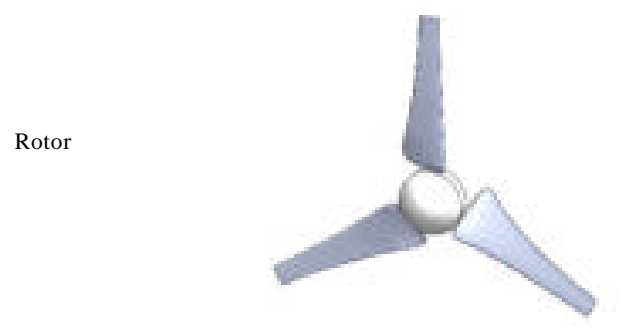

Diffuser $\left(\theta_{\mathrm{f}}=0\right)$

Diffuser $\left(\theta_{\mathrm{f}}=5\right)$

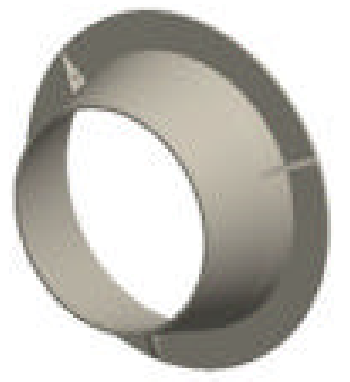

(b)
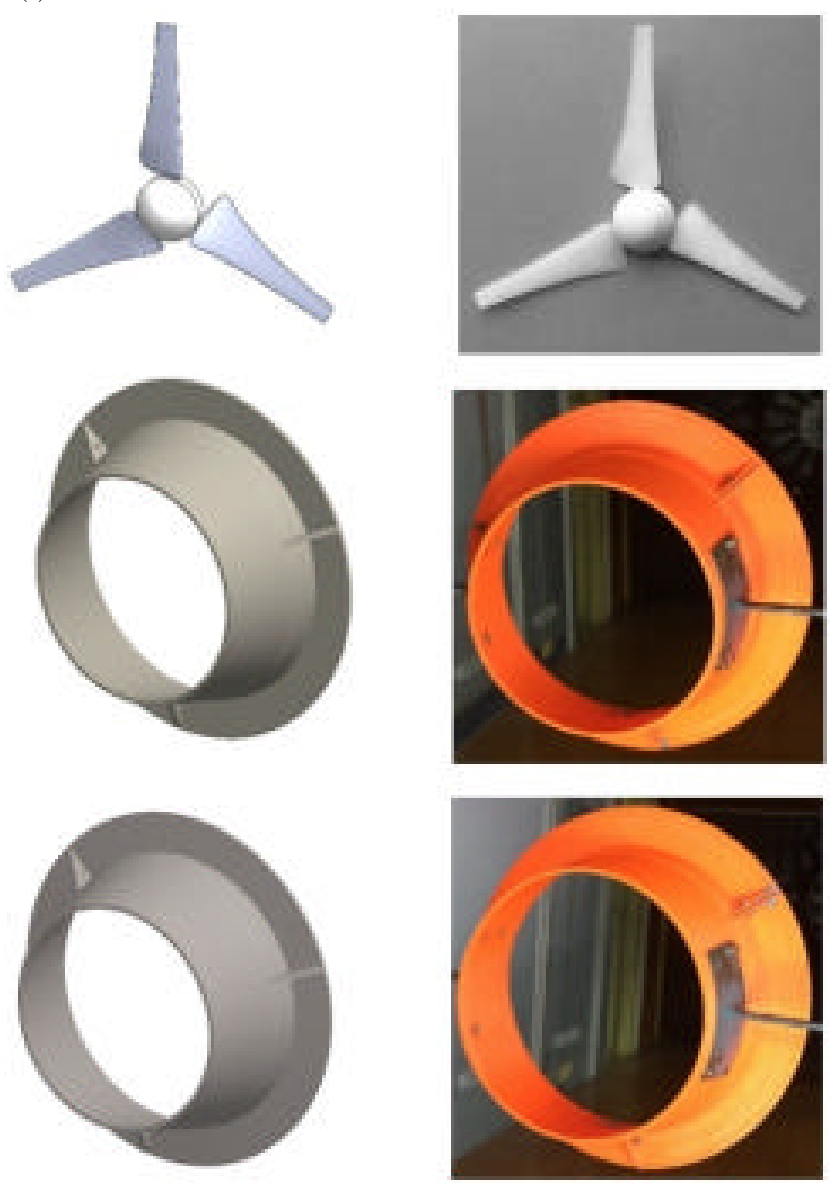

Fig. 2: Rotor and flanged diffusers models: a) Modelling models and b) Prototype models

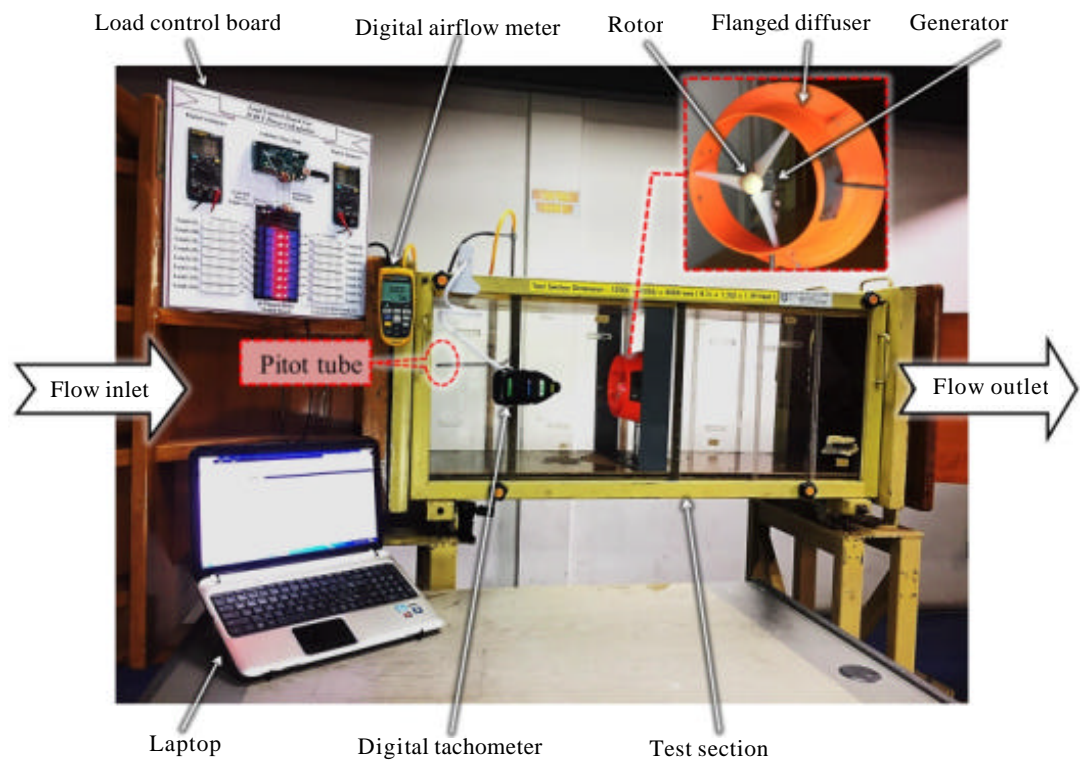

Fig. 3: The experimental set up testing of FDAWT 
using a load control board that has been used in own previous study (Al-quraishi et al., 2019). In this board, 16 of $12 \mathrm{~V}, 1 \mathrm{~W}$ LEDs load were utilized and connected as a series electrical circuit. Since, the power generated is equal to multiplier voltage into the current, tow of ANEGN AN8002 AC/DC digital multi-meters connected directly across the output power of the generator to record the voltage and the current for each loading case.

The experimental setup are shown in Fig. 3. The generator of the turbine is connected to load, the voltmeters were used to measure the voltage and current across the load. By maintaining air velocity is constant, the load can be varied by operating more load (LEDs), the voltage and current were recorded at each load. At the same time, the angular velocity is recorded at each load. The experiment was repeated several times based on cases of the models. The experiments for the two models of FDAWT $\left(\bullet_{\mathrm{f}}=0^{\circ}\right.$ and $\left.\bullet_{\mathrm{f}}=5^{\circ}\right)$ were conducted at wind speeds 7 and $8 \mathrm{~m} / \mathrm{sec}$.

Since, wind power is source the mechanical power of wind turbine which is the product of rotor torque and angular velocity of rotor. So, the wind turbine performance is represented by the power Coefficient $\left(\mathrm{C}_{\mathrm{P}}\right)$ which is defined as:

$$
\mathrm{C}_{\mathrm{p}}=\frac{\mathrm{P}_{\text {out }}}{\mathrm{P}_{\text {wind }}}=\frac{\mathrm{Q} \Omega}{0.5 \rho \mathrm{AV}_{\infty}^{3}}
$$

The most common method used to preview the power coefficient by graphing its values as function with tip speed ratio $(\bullet)$ which is defined as:

$$
\lambda=\frac{\Omega R}{V \infty}
$$

Moreover, torque Coefficient $\left(\mathrm{C}_{\mathrm{Q}}\right)$ can be considered as parameters for study turbine performance, especially, for DAWT (Meri et al., 2019; Kosasih and Hudin, 2016). Thus, $\mathrm{C}_{\mathrm{Q}}$ as a function of $\mathrm{C}_{\mathrm{P}}$ defined as:

$$
\mathrm{C}_{\mathrm{Q}}=\frac{\text { Actual torque }}{\text { Theoretical torque }}=\frac{\mathrm{Q}}{0.5 \rho \mathrm{AV}_{\infty}^{2}}=\frac{\mathrm{C}_{\mathrm{p}}}{\lambda}
$$

Where:

$$
\begin{aligned}
\mathrm{Q} & =\text { Actual rotor torque } \\
\mathbf{B} & =\text { Angular velocity } \\
\mathbf{B} & =\text { Air density } \\
\mathrm{A} & =\text { Rotor swept Area } \\
\mathrm{V} \cdot & =\text { Upstream wind Velocity } \\
\mathrm{R} & =\text { Rotor radius }
\end{aligned}
$$

Simulation description: Computational Fluid Dynamics (CFD) approach also is employed to simulate of FDAWT

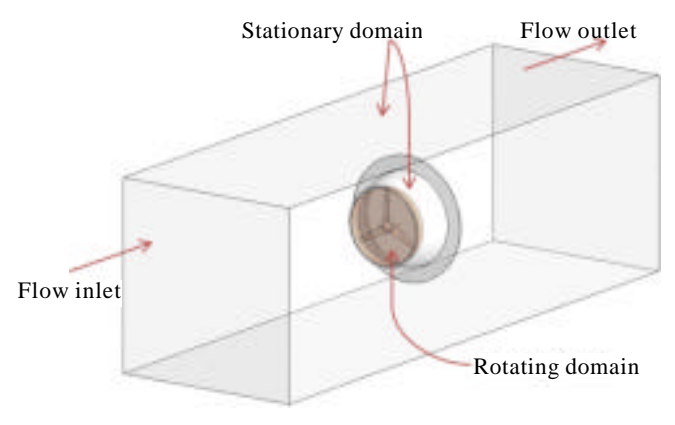

Fig. 4: The 3D simulation domain of FDAWT

for performance calculations in terms of power, $\mathrm{C}_{\mathrm{P}}$ and $\mathrm{C}_{\mathrm{Q}}$. 3D CFD Model was used which is a virtual copy of actual test section of wind tunnel. ANSYS CFX 19.1 solver was used to investigate the flow over full geometry of FDAWT, in the two configurations of flange angles, 0 and $5^{\circ}$. The models of rotor and diffuser were modeled in sold work then imported to the design modeller in ANSYS while the domain of virtual test section was constructed around FDAWT. The simulation was carried out in a steady-state. The flow was treated as isothermal. The working fluid is air as ideal gas and the reference pressure is $1 \mathrm{~atm}$ at default turbulence intensity (Al-quraishi et al., 2019). The computational field consists of two regions, a stationary and a rotating domain as shown in Fig. 4. The stationary domain is the virtual wind tunnel and flanged diffuser. The rotating domain consist of HAWT rotor enclosed in the rotating frame (disc). The support system of the rotor inside the diffuser was not included. The interface model between the stationary and rotating frames that adopted is frozen rotor with automatic pitch change (Tourlidakis et al., 2013; Kosasih and Hudin, 2016). The wall of tunnel, surfaces of the diffuser's walls, the rotor blades and the hub of the rotor are considered as no slip walls. At the inlet of the computational field the wind velocity was fixed and at the outlet a relative static pressure equal to $0 \mathrm{~Pa}$ was set. The rotating domain set to the selected rotational velocity.

The turbulence model which adopted is (SST k-w) which give a very good prediction for the results (Menter, 1994) as well as it has been used by Tourlidakis et al. (2013), Kosasih and Hudin (2016), Elbakry et al. (2016) and Michal et al. (2016). The residual target of convergence criterion is set at $10^{\bullet^{4}}$. The mesh type was Tetrahedron with (5228912) elements and (1197246) nodes for FDAWT with $\bullet_{\mathrm{f}}=0^{\circ}$ model while numbers of elements and nodes for model of FDAWT with ${ }_{\mathrm{f}}=5^{\circ}$ were (5289118) and (1217244), respectively. The skewness was 0.79 and orthogonal quality $(0.997)$. The mesh for the models of FDAWT are show in Fig. 5. 

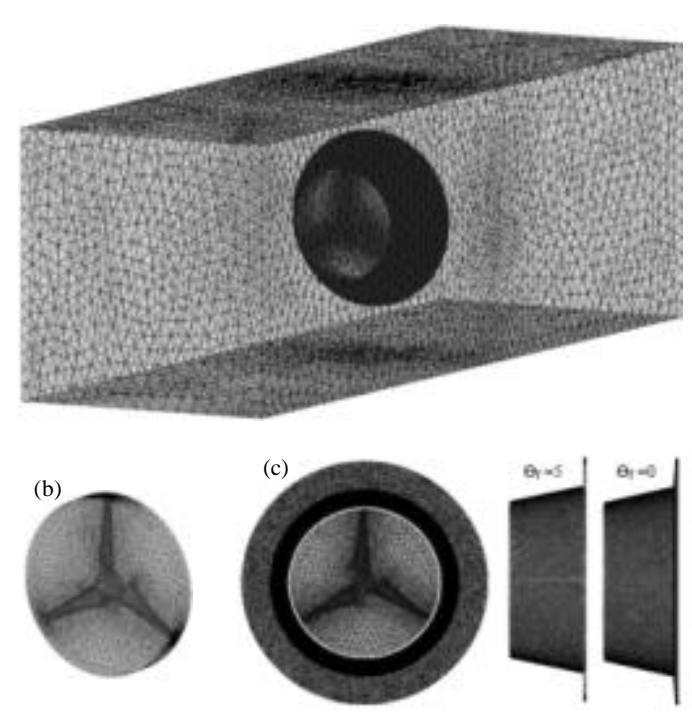

Fig. 5: Mesh of: a) Full domain and b) Rotating domain and FDAWT (rotor and flanged diffuser)

\section{RESULTS AND DISCUSSION}

The results of experimental and CFD simulation of FDAWT are mention in this study. The results are exhibited in terms of $\mathrm{P}_{\text {out }}, \mathrm{C}_{\mathrm{P}}$ and $\mathrm{C}_{\mathrm{Q}}$ which is comparing with the test results for BHAWT and NFDAWT at own previous study (Al-quraishi et al., 2019).

Power of FDAWT: The mechanical Power $\left(\mathrm{P}_{\text {out }}\right)$ of FDAWT was calculated experimentally from the voltage and current recorded at each load with considering values for the mechanical and conversion efficiencies for the generator. The angular velocity can be measured experimentally using tachometer in $\mathrm{rpm}$, so, the actual torque can be calculated. In CFD, to calculate the power extracted by the turbine, must be know a two components are torque and angular velocity of the rotor. The rpm that measured experimentally was adopted while an expression is used to calculate the rotor torque which available in CFD-post.

The experimental tests and CFD simulation for FDAWT were conducted at two velocities 7 and $8 \mathrm{~m} / \mathrm{sec}$ for both configurations of flange, ${ }_{\mathrm{f}}=0^{\circ}$ and $\bullet_{\mathrm{f}}=5^{\circ}$. The results showed a significant increase of power for the two configurations as compared with NFDAWT and BHAWT. Figure 6 and 7, respectively, show the experimental data of a comparison FDAWT power curves with NFDAWT and BHAWT (presented in previous study) at up stream wind velocity of 7 and $8 \mathrm{~m} / \mathrm{sec}$. From Fig. 6 , and 7, it can see the power is increase with rpm increased until reached to maximum power values. At $\mathrm{V}$. $=7 \mathrm{~m} / \mathrm{sec}$, the maximum

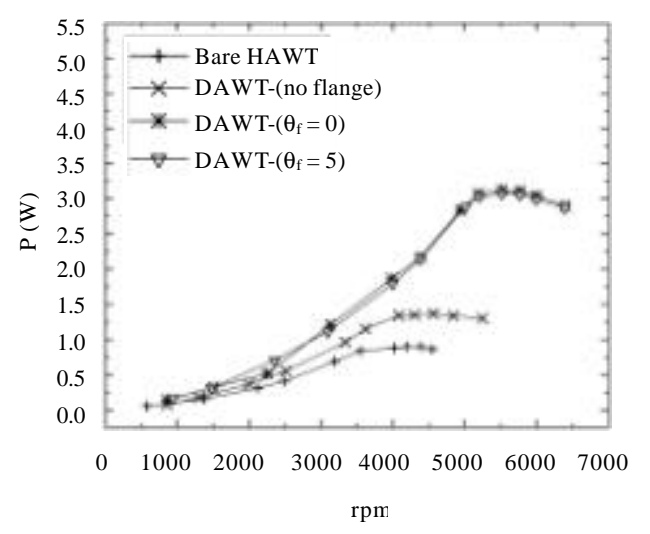

Fig. 6: The experiments data of FDAWT power as function of rpm compared to NFDAWT and BHAWT at wind velocity of $7 \mathrm{~m} / \mathrm{sec}$

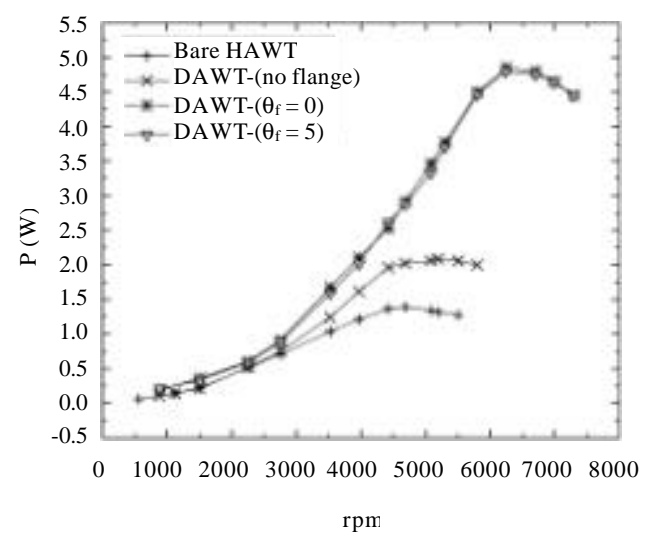

Fig. 7: The experiments data of FDAWT power as function of rpm compared to NFDAWT and BHAWT at wind velocity of $8 \mathrm{~m} / \mathrm{sec}$

power value recorded for FDAWT with ${ }_{\mathrm{f}}=0^{\circ}$ and $\bullet_{\mathrm{f}}=5^{\circ}$ were 3.129 and $3.074 \mathrm{~W}$, respectively. The maximum power of FDAWT at V. $=8 \mathrm{~m} / \mathrm{sec}$ were 4.85 and $4.8 \mathrm{~W}$ for ${ }_{\mathrm{f}}$ of $0^{\circ}$ and $5^{\circ}$, respectively. The results show great affinity in performance for the two flange configurations of FDAWT. For the both values of wind speeds, the power of FDAWT increases by $1.24-1.3$ over NFDAWT with ${ }_{\mathrm{f}}$ of $5^{\circ}$ while reach to 1.326 with ${ }_{\mathrm{f}}$ of $0^{\circ}$.

The performance of FDAWT: Since, power coefficient indicate to the wind turbine performance, so, the results of experiments and CFD for FDAWT focused to measure $\mathrm{C}_{\mathrm{P}}$ at various ranges of rotational speed. The measured $\mathrm{C}_{\mathrm{P}}$ values of the both FDAWT configurations, ${ }_{\mathrm{f}}=0^{\circ}$ and ${ }_{\mathrm{f}}=5^{\circ}$ were plotted as a function of $\cdot$ in Fig. 8 and 9 , respectively. The results were recorded at wind velocity of $7 \mathrm{~m} / \mathrm{sec}$ and compared to previous design (NFDAWT). As can be seen from these plots, the FDAWT has much 


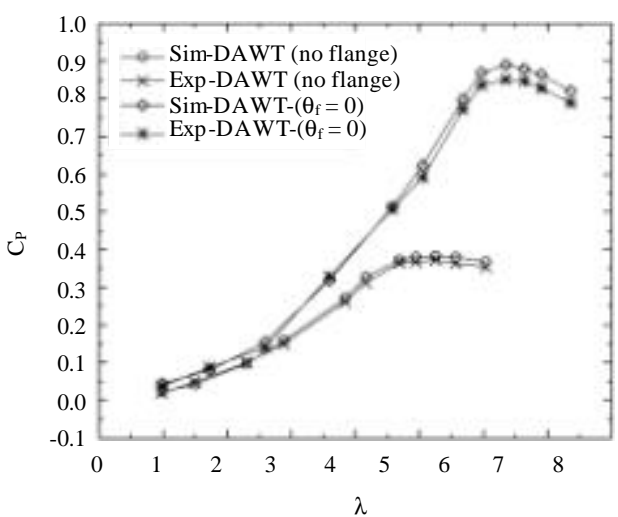

Fig. 8: The power coefficient, $\mathrm{C}_{\mathrm{p}} \mathrm{vs}$. tip speed ratio, $\bullet$ for FDAWT with $\bullet_{\mathrm{f}}=0^{\circ}$ compare to NFDAWT

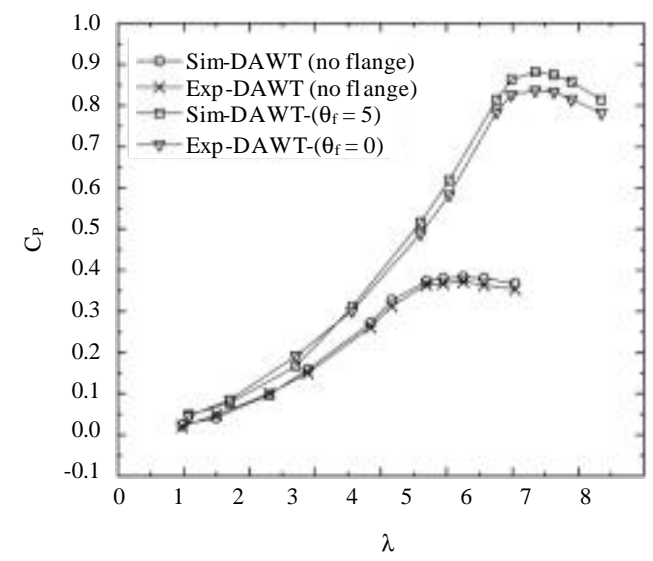

Fig. 9: The power coefficient, $\mathrm{C}_{\mathrm{P}}$ vs. tip speed ratio, $\bullet$ for FDAWT with ${ }_{\mathrm{f}}=5^{\circ}$ compare to NFDAWT

higher $\mathrm{C}_{\mathrm{p}}$ than NFDAWT. This is because presence of flange at diffuser outlet which is causes to generate a vortices in wind flow near of flange wall. The vortices generated caused a suction for the flow through the diffuser, hence, more flow at rotor plane. Increasing of wind velocity at rotor plane led to make the rotor rotate faster, hence, the torque of FDAWT increase to some extent as compared of NFDAWT rotor torque.

As the presence of flange at diffuser outlet increase the power coefficient of FDAWT, its also causes a jump in the tip speed ratio. The trends of the both flanges configurations are a same in behaviour but still there is a little difference. FDAWT with ${ }_{\mathrm{f}}$ of $0^{\circ}$ has the maximum $\mathrm{C}_{\mathrm{P}}$ of 0.851 at - of 6.35 which is pretty close to value of - for FDAWT with ${ }_{\mathrm{f}}$ of $5^{\circ}$ at which there the maximum $\mathrm{C}_{\mathrm{p}}$ of 0.836. Despite the slight differences between the values of $\mathrm{C}_{\mathrm{p}}$ for the two configurations of FDAWT they seem to be convergent. On another hand, the torque Coefficient $\left(\mathrm{C}_{\mathrm{Q}}\right)$ can be one of the performance parameters of wind turbine. The torque coefficient of FDAWT is greater compared to

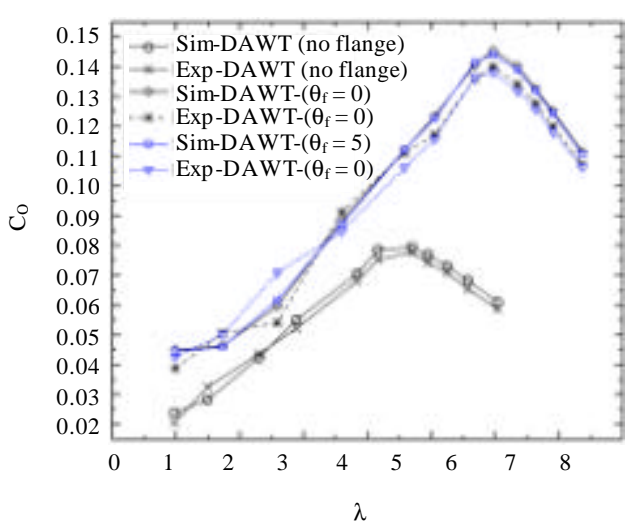

Fig. 10: The torque coifficient, $\mathrm{C}_{\mathrm{Q}}$ vs. tip speed ratio, $\bullet$ for NFDAWT compare to FDAWT with $\left(\bullet_{\mathrm{f}}=0^{\circ}\right)$ and $\left(\bullet_{\mathrm{f}}=5^{\circ}\right)$ at $\mathrm{V}_{8}=7 \mathrm{~m} / \mathrm{sec}$

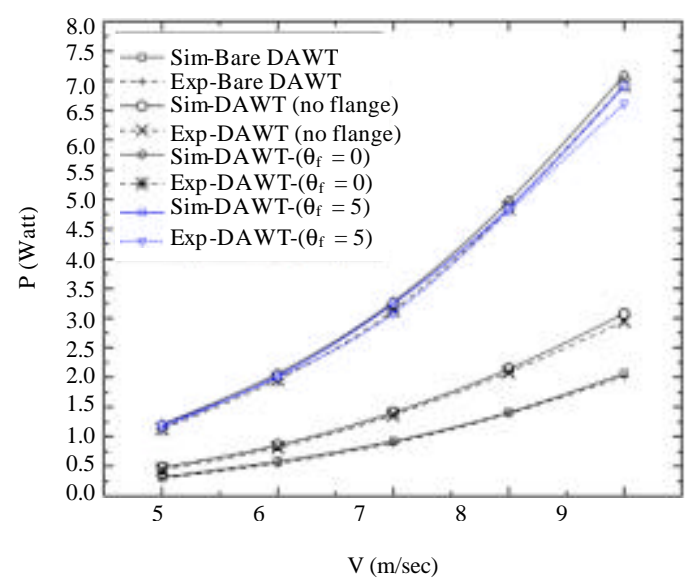

Fig. 11: The maximum Power of FDAWT compare to NFDAWT and BHAWT at different wind velocities

NFDAWT. The maximum $\mathrm{C}_{\mathrm{Q}}$ for FDAWT at ${ }_{\mathrm{f}}$ of 0 and $5^{\circ}$ were 0.14 and 0.138 , respectively while it was 0.077 for NFDAWT as shown in Fig. 10 where the data recorded at wind velocity of $7 \mathrm{~m} / \mathrm{sec}$. In addition, it can be noted from the graphs there are a well pretty agree for the CFD simulations with the experiments data (Fig. 11-13).

The maximum mechanical power for FDAWT as a function of wind velocity for a range from $5-9 \mathrm{~m} / \mathrm{sec}$ is shown in Fig. 11. This range of velocities have been considered due to the generator limits, unable to convert all of the generated torque on the rotor to mechanical power. On other hand, the velocities that below of $5 \mathrm{~m} / \mathrm{sec}$ unable to rotate rotor in case of connect a load to the generator. It is interesting to note that even though the maximum power out increases with increase of wind velocity but it is always look same increase for all wind 
J. Eng. Applied Sci., 14 (Special Issue 5): 9162-9170, 2019

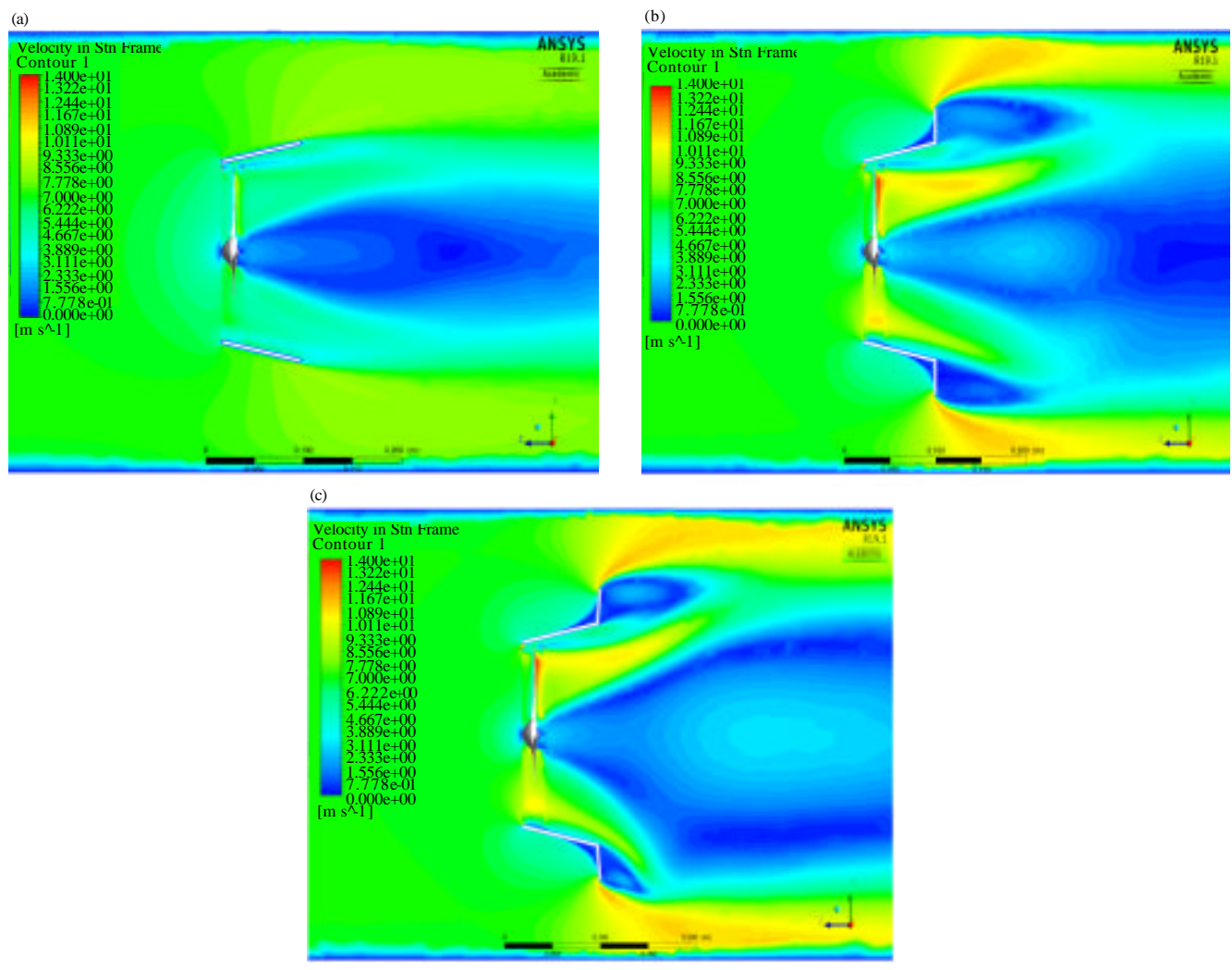

Fig. 12: Velocity contoure in: a) NFDAWT; b) FDAWT $\left(\bullet_{\mathrm{f}}=0^{\circ}\right)$ and c) $\operatorname{FDAWT}\left(\bullet_{\mathrm{f}}=5^{\circ}\right)$

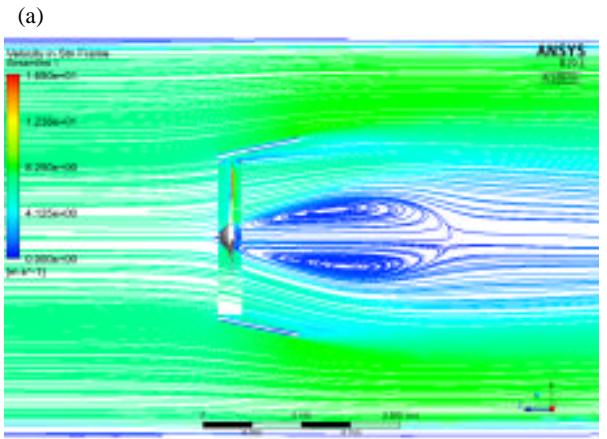

(b)

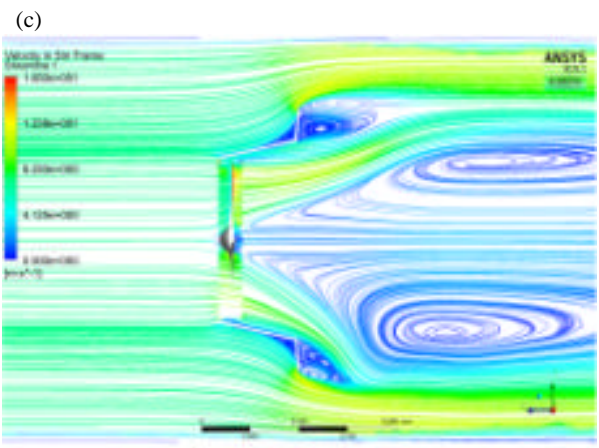

Fig. 13: Velocity streamline in: a) NFDAWT; b) FDAWT $\left(\bullet_{\mathrm{f}}=0^{\circ}\right)$ and c) FDAWT $\left(\bullet_{\mathrm{f}}=5^{\circ}\right)$ 
velocities for the two configurations of FDAWT. In another hand, Fig. 11 also show a comparison of maximum power for FDAWT to NFDAWT and BHAWT. This comparison give a clear vision for augmentation of the wind turbine power by using FDAWT.

CFD simulation visualizations: The CFD simulation provide a good vision for visualize the velocity distribution for FDAWT in the two flanges angles $(0$ and $5^{\circ}$ ) and compared to NFDAWT. All of the visualization contours were captured at inlet flow velocity of $7 \mathrm{~m} / \mathrm{sec}$ and - around 5 in same boundary conditions mentioned in simulation description section.

Figure 12 and 13 show the velocity contour and velocity streamline, respectively, easy to observed effect of exist the flange at diffuser outlet. The flow through NFDAWT appears a little increase for wind velocity at rotor plane while the velocity increase reached to a high levels in FDAWT for both flange configurations.

Presence of flange causes a separation of flow behind the flange due to the significant drop in pressure. Since, the wind tend to flowing from high to low pressure area, a group of vortices are generated nears of flanges wall causes flow suction speedily there is a bit different in flow behaviour for the flangeconfigurations. This is due to the small vortices near of flange wall were generated in case of ${ }_{\mathrm{f}}=0^{\circ}$ at a distance less of the case of ${ }_{\mathrm{f}}=5^{\circ}$. Hence, the FDAWT with $\bullet_{\mathrm{f}}=0^{\circ}$ have produce greater power compare to other configurations.

\section{CONCLUSION}

In this study, a small scale model of Flanged Diffuser Augmented Wind Turbine (FDAWT) has been presented in a two flanges configurations with ${ }_{\mathrm{f}}$ of $0^{\circ}$ and ${ }_{\mathrm{f}}$ of $5^{\circ}$. The models were fabricated and tested in the wind tunnel. The experimental performance tests were conducted using a method based on a load board control to calculate voltage and current produced from the generator at each round (load add). The power of FDAWT was investigated at a two wind velocities 7 and $8 \mathrm{~m} / \mathrm{sec}$ as a function to rpm.

The performance FDAWT was investigate and CFD validate at $7 \mathrm{~m} / \mathrm{sec}$ of flow velocity in terms of $\mathrm{C}_{\mathrm{P}}$ and $\mathrm{C}_{\mathrm{Q}}$ as a function to tip speed ratio, $\bullet$. The results show that a significant increase in the $\mathrm{C}_{\mathrm{P}}$ of FDAWT for the two configurations compare to NFDAWT. This increase due to presence of flange at outlet diffuser where a vortices are generate near the flange wall causes flow suction which led to augmented the flow velocity at rotor plane. As increase of wind velocity at rotor plane, the rotor rpm increase, hence, more power generated. Moreover, the maximum power of FDAWT with $\bullet_{\mathrm{f}}$ of $0^{\circ}$ and ${ }_{\mathrm{f}}$ of $5^{\circ}$ were calculated for a different wind velocities ranged of $5-9 \mathrm{~m} / \mathrm{sec}$. The results show an increasing in power with increased of wind velocity but this increase look in same behaviour at all velocities range for the two configurations of FDAWT. On another hand, the results show a power augmentation of FDAWT in range of 1.24 to 1.58 times over NFDAWT and 2.3-2.8 times over BHAWT for same rotor. The experiments results for all cases were validated with CFD simulation within accepted error ratio. Also the CFD provided a visualization for the flow across wind turbine.

\section{REFERENCES}

Al-quraishi, B.A., N.Z.B. Asmuin, M.N. Nemah and A.S. Meri, 2019. Experimental and simulation investigation for performance of a small-scale model of bare and shrouded HAWT. Intl. J. Mech. Eng. Technol., 10: 434-449.

Anonymous, 2006. Fluke 922 airflow meter user manual. Fluke Corporation, Everett, Washington, USA. https://dam-assets.fluke.com/s3fs-public/922 umeng 0100 .pdf

Anonymous, 2019. RS 445-9557: Laser, photo tachometer. Manualslib, Florida, USA. https://webcache. googleusercontent. com/search?q=cache:cZFvGRS eCvEJ:https://www.manualslib.com/manual/138582 $1 / \mathrm{Rs}-445-9557 \cdot \mathrm{html}+\& \mathrm{~cd}=3 \& \mathrm{hl}=\mathrm{en} \& \mathrm{ct}=\mathrm{clnk} \& \mathrm{gl}=\mathrm{pk}$

El-Zahaby, A.M., A.E. Kabeel, S.S. Elsayed and M.F. Obiaa, 2017. CFD analysis of flow fields for shrouded wind turbines diffuser model with different flange angles. Alexandria Eng. J., 56: 171-179.

Elbakry, H.M., A.A. Attia, O.E. Abdelatif and M.S. Zahran, 2016. Simulation of diffuser augmented wind turbine performance. Proceedings of the 2016 World Congress on Sustainable Technologies (WCST), December 12-14, 2016, IEEE, London, UK., ISBN:978-1-4673-8935-8, pp: 40-48.

Gipe, P., 1999. Wind Energy Basics, A Guide to Small and Micro Wind Systems. Chelsea Green Publishing Company, USA.

Goltenbott, U., Y. Ohya, S. Yoshida and P. Jamieson, 2017. Aerodynamic interaction of diffuser augmented wind turbines in multi-rotor systems. Renewable Energy, 112: $25-34$.

Igra, O., 1981. Research and development for shrouded wind turbines. Energy Conversion Manage., 21: $13-48$.

Jafari, S.A.H. and B. Kosasih, 2014. Flow analysis of shrouded small wind turbine with a simple frustum diffuser with computational fluid dynamics simulations. J. Wind Eng. Ind. Aerodynamics, 125: 102-110. 
Kardous, M., R. Chaker, F. Aloui and S.B. Nasrallah, 2013. On the dependence of an empty flanged diffuser performance on flange height: Numerical simulations and PIV visualizations. Renewable Energy, 56: 123-128.

Kosasih, B. and A. Tondelli, 2012. Experimental study of shrouded micro-wind turbine. Procedia Eng., 49: 92-98.

Kosasih, B. and H.S. Hudin, 2016. Influence of inflow turbulence intensity on the performance of bare and diffuser-augmented micro wind turbine model. Renewable Energy, 87: 154-167.

Lee, M.H., Y.C. Shiah and C.J. Bai, 2016. Experiments and numerical simulations of the rotor-blade performance for a small-scale horizontal axis wind turbine. J. Wind Eng. Ind. Aerodyn., 149: 17-29.

Libii, J.N. and D.M. Drahozal, 2012. The influence of the lengths of turbine blades on the power produced by miniature wind turbines that operate in non-uniform flow fields. World Trans. Eng. Technol. Educ., 10: 128-133.

Menter, F.R., 1994. Two-equation eddy-viscosity turbulence models for engineering applications. AIAA J., 32: 1598-1605.

Meri, S.A.R., H.B.B. Salleh, M.N. Nemah and B.A. Al-Quraishi, 2019. Performance evaluation of Savonius wind turbine based on a new design of blade shape. Intl. J. Mech. Eng. Technol., 10: 837-846.

Michal, L., K. Maciej and J. Krzysztof, 2016. Analysis and comparison of numerical methods for design and development of small Diffuser-Augmented Wind Turbine (DAWT). Proceedings of the IECON 2016 42nd International Annual Conference on IEEE Industrial Electronics Society, October 23-26, 2016, IEEE, Florence, Italy, ISBN:978-1-5090-3475-8, pp: 5525-5531.
Ohya, Y., 2014. Bluff body flow and vortex-its application to wind turbines. Fluid Dyn. Res., 46: $1-14$.

Ohya, Y., T. Karasudani, A. Sakurai, K.I. Abe and M. Inoue, 2008. Development of a shrouded wind turbine with a flanged diffuser. J. Wind Eng. Ind. Aerodynamics, 96: 524-539.

Ohya, Y., T. Karasudani, T. Nagai and K. Watanabe, 2017. Wind lens technology and its application to wind and water turbine and beyond. Renewable Energy Environ. Sustainability, 2: 1-6.

Peacock, A.D., D. Jenkins, M. Ahadzi, A. Berry and S. Turan, 2008. Micro wind turbines in the UK domestic sector. Energy Build., 40: 1324-1333.

Soomro, B.A., A. Ahmed and A. Hussain, 2016. Modelling and simulation of Diffuser Augmented Wind Turbine (DAWT). Proceedings of the 4th International Conference on Energy Environment and Sustainable Development (EESD2016), December 15, 2016, Mehran UET, Jamshoro, Sindh, Pakistan, pp: $1-8$.

Tourlidakis, A., K. Vafiadis, V. Andrianopoulos and I. Kalogeropoulos, 2013. Aerodynamic design and analysis of a flanged diffuser augmented wind turbine. Proceedings of the ASME 2013 International Conference and Exposition on Turbo Expo, June 3-7, 2013, Honors and Awards San Antonio, Texas, USA., ISBN:978-0-7918-5529-4, pp: 1-10.

Wang, W.X., T. Matsubara, J. Hu, S. Odahara and T. Nagai et al., 2015. Experimental investigation into the influence of the flanged diffuser on the dynamic behavior of CFRP blade of a shrouded wind turbine. Renewable Energy, 78: 386-397. 